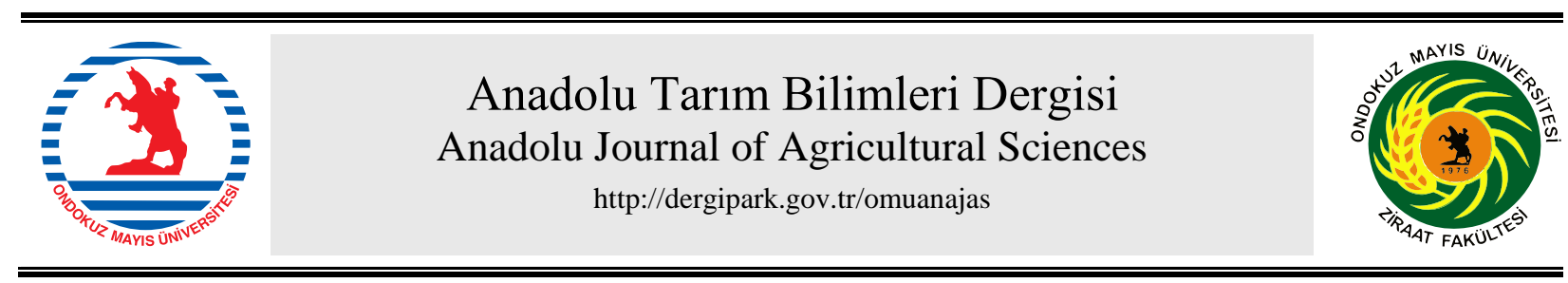

Araştırma/Research

Anadolu Tarım Bilim. Derg./Anadolu J Agr Sci, 35 (2020)

ISSN: 1308-8750 (Print) 1308-8769 (Online)

doi: 10.7161/omuanajas.661631

\title{
Sarmalık kıyılmış tütünlerde uygulanan tarımsal işlemler ve kalite özelliklerinin
} belirlenmesi

\author{
๑Serhat Kanoglu ${ }^{\mathrm{a}}$, ๑Ahmet Kınay ${ }^{\mathrm{a}}$, ๑Erdem Karakoç \\ ${ }^{a}$ Tokat Gaziosmanpaşa Üniversitesi, Ziraat Fakültesi, Tarla Bitkileri Bölümü, Tokat, Turkey
}

*Sorumlu yazar/corresponding author: serhat_kanoglu@hotmail.com

Geliş/Received 19/12/2019 Kabul/Accepted 04/03/2020

\begin{abstract}
ÖZET
Bu araştırmanın amacı Türkiye'de üretilmekte olan sarmalık kıyılmış tütünlerin kimyasal içeriklerini ve bunların referans sınır değerler içerisindeki yerini belirlemektir. Çalışma sarmalık kıyılmış tütünlerin yoğun olarak üretildiği Doğu ve Güneydoğu Anadolu (Mardin, Diyarbakır, Hatay, Muş, Bitlis, Batman, Adıyaman ve Malatya) bölgelerinde 2016-2017 yıllarında yürütülmüştür. Araştırmada yöreyi temsil edecek şekilde belirlenen 30 noktadan kuru yaprak tütün örnekleri toplanarak kimyasal kompozisyonları tespit edilmiştir. Çalışmada tütün yapraklarında kükürt ve nikotin içeriklerinin referans değerlerin üstünde, kadmiyum ile arseniğin ise referans sınır değerlerin içerisinde olduğu belirlenmiştir. Tütünde kaliteyi olumlu yönde etkileyen glikoz, klorojenik asit ve rutin oranlarının ise kalite tipi tütünlere göre düşük olduğu görülmüştür. Türkiye'deki sarmalık kıyılmış tütün üretiminde oryantal tütün üretiminin aksine seyrek dikim, daha fazla sulama-gübreleme yapıldığı ve yoğun kükürt kullandığı tespit edilmiştir. Tarımsal üretimdeki bu farklılıklar tütünlerin kimyasal kompozisyonunu doğrudan etkilemiştir. Bunun sonucunda da tütünlerde nikotin oranı ve kükürt içeriklerinin yüksek olduğu belirlenmiştir.
\end{abstract}

\section{Determination of Quality Properties and Applied Agricultural Practice In Roll Your Own Tobacco}

\section{ABSTRACT}

The aim of this study is to determine the chemical content of roll-your-own tobacco produced in Turkey and its position within the reference limit values. The study was conducted in the regions of Eastern and Southeastern Anatolia (Mardin, Diyarbakır, Hatay, Mus, Bitlis, Batman, Adiyaman and Malatya) where roll-your-own tobacco is produced intensively in 2017. The chemical compositions is determined by collecting dry tobacco leaf samples from 30 spots in such a way that determined to represent the region. In this study, it is determined that sulfur and nicotine content in tobacco leaves are above reference limit values whereas cadmium and arsenic are within the reference limit values. Glucose, chlorogenic acid and routine rates that affect quality positively in tobacco are determined to be low when compared to quality type tobacco. In the production of roll-your-own tobacco in Turkey, it is determined that sparse planting, more irrigation-fertilization and intensive sulfur are used, contrary to oriental tobacco production. These differences in agricultural production directly affect the chemical composition of tobacco. As a result, it is determined that nicotine rate and sulphur contents are high in tobacco.

Keywords: Phenolics Sulfur Cadmium Nicotine 


\section{Giriş}

Dünya ve Türkiye'de üretilmekte olan tütünler genellikle sigara yapımında kullanılmaktadır. Türkiye'nin Doğu ve Güneydoğu Anadolu Bölgelerinde fabrikasyon işlemlerine tabi tutulmadan kıyılıp sarılmak suretiyle tüketilen tütün üretimi de yapılmaktadır. Sigara üretimi belirli bir programa göre üretilip kontrollerden geçirilerek piyasaya sürülmektedir. Ancak sarmalık kıyılmış tütünler piyasada herhangi bir prosedüre ve kontrol işlemine tabi tutulmadan doğrudan satılabilmektedir. Türkiye piyasasında üretilen ve tüketilen sarmalık kıyılmış tütünlerin kimyasal içerikleri ve bunların referans sınır değerler içerisindeki yeri bilinmemektedir.

Sigara dumanının ana bileşenleri, azot, oksijen ve karbonmonoksittir. Yaklașık 4000 kimyasal maddenin bulunduğu sigaranın önemli toksik bileşenleri nikotin ve kadmiyumdur (Söylemez, 2011). Kadmiyum, vücuttan atılımı oldukça yavaş olan, biyolojik yarılanma ömrünün 10-30 yıl arasında olduğu tahmin edilen bir ağır metaldir. Kadmiyum kadar zararlı olan nikotin tütün bitkisi tarafından üretilen bir alkaloittir (Ayan, 2008). Tütün içeriğindeki kükürt ile ilgili çalışmalar yapılmış olsa da dünyaca ön görülen bir sınır değeri tam olarak verilmemiștir. Tütün gibi kayısı yetiştiriciliğinde de sarartma amaçlı kükürt kullanılmaktadır. Bu nedenle kükürt içeriği için kıstas olarak Türk Standartları Enstitüsü'nün (TSE) 01.08.1993 tarihinde ve TS/485 sayılı ile yürürlüğe giren kuru kayısı ihracat yönetmeliği örnek alınabilmektedir. Yönetmeliğe göre $\% 0.25$ kükürt oranı istenmektedir. Ayrıca kuru kayısı ithalatı yapan ülkeler içerisinde Almanya, İngiltere, Fransa gibi ülkeler 2000 ppm sınır isterken, Avustralya gibi bazı ülkeler 3000 ppm düzeyini kabul etmektedirler (Üren, 2011). Sarmalık kıyılmış tütünler için bu çalışmada 3000 ppm düzeyi belirleyici olarak alınmıştır.

Kuru tütün yaprağının ve sigara dumanının içeriği üzerine bazı araştırmalar yapılmıştır. Yapılan çalışmalara göre; kadmiyum $110 \mu \mathrm{g}$ (mikrogram), çinko $60 \mu \mathrm{g}$, asetik asit 330-810 gg (gigagram), nikotin 1.0$2.5 \mathrm{mg}$ (miligram), fenol 60-140 gg (gigagram) olarak bulunmuştur (Er, 2016). Ayrıca, kanserojen olduğu bilinen 4-Aminobifenil $4.6 \mu \mathrm{g}$, arsenik, benzen 12-48 gg, krom, nikel 20-80 $\mu$ g miktarlarında tespit edilmiştir (Aşut, 1993; Zhu ve ark., 1996; Kayaalp, 1997; Gazioğlu, 1997; Fitzpatrick ve Blair, 2000). Birleşik Krallık ve Kore' de sigara markalarında yapılan incelemelerde bulunan değerler sırasıyla arsenik 0.12$0.23 \mu \mathrm{g}$, kadmiyum 0.90-1.02 $\mu \mathrm{g}$, bakır 7.73-13.0 $\mu \mathrm{g}$, kurşun 0.74-1.35 $\mu \mathrm{g}$ ve çinko 31.9-38.5 $\mu \mathrm{g}$ değerleri arasında ölçülmüsştür (Jung ve ark., 1998). Bulunan bu değerler sınır referans değerlerin altında olduğu görülmüştür. Türkiye'de 1981 yılından itibaren her bir sigaradaki nikotinin $1.3 \mathrm{mg}$ sinırının altında olması gerektiği öngörülmüştür (Oral, 2010). 2008 Tarih ve 27065 sayılı resmi gazetede değişiklik ile zifir $10 \mathrm{mg}$, nikotin $1 \mathrm{mg}$ ve karbon monoksit $10 \mathrm{mg}$ değerinin altında olması gerektiği tebliğ edilmiştir. Ayrıca ağır metal referans değerleri her bir sigarada kadmiyum 1.7 $\mu \mathrm{g}$, kurşun $2.4 \mu \mathrm{g}$, arsenik $0.23 \mu \mathrm{g}$, bakır $15.6 \mu \mathrm{g}$, çinko 49.7 gg olarak ifade edilmektedir (Mussalo-Rauhamaa ve ark., 1986).

Yapılan araştırma sonucunda bölgede yetiştirilen sarmalık kıyılmış tütünlerin kükürt ve nikotin içeriklerinin referans değerlerin üzerinde olduğu belirlenmiştir. Yörede üretilen tütünlerde kullanılan yoğun gübre ve kükürt kullanımı nikotin ve kükürt değerlerinin yüksek olmasını sağladığı düşünülmektedir. Türkiye'de üretilmekte olan sarmalık kıyılmış tütünlerin, ülkede uygulanmakta olan sözleşmeli üretimin dışında, yetiştiricilik ve devamındaki sürecin kendi haline bırakılması standart değerlerin dışında bir tütün mamulünün piyasada yer aldığını göstermektedir.

\section{Materyal ve Yöntem}

$\mathrm{Bu}$ araştırma 2016-2017 yıllarında Doğu ve Güneydoğu Anadolu Bölgelerinde sarmalık kıyılmış tütün üretimi yapılan Muş, Diyarbakır, Batman, Malatya, Adiyaman, Bitlis, Hatay, Mardin illerinde yürütülmüştür.

Çalışmada kümeleme örnekleme yöntemine göre belirtilen 8 ilde $(\mathrm{n} * \mathrm{~S} 2 * \mathrm{t} 2 /(\mathrm{n}-1) * \mathrm{~d} 2+\mathrm{S} 2 * \mathrm{t} 2)$ belirlenen 30 noktadan örnekleme yapılmıştır. (n: küme sayısı, S2: standart sapma, t2: $\mathrm{T}$ tablo değeri (\%5'e göre) ve d2: ort. $\left.{ }^{*} 0.1\right)$. Bu 30 nokta illerdeki tütün üretim alanı ve üretici sayısına göre belirlenmiştir (Çiçek ve Erkan, 1996). Kuru tütün yaprağı örnekleri bahsi geçen illerden yöreyi temsil edecek şekilde belirtilen noktalardan alınmıștır. Toplanan örneklere ait nikotin oranları, HPLC cihazında $250 \times 4.6 \mathrm{~mm}$ ve $5.0 \mathrm{~mm}$ partikül büyüklüğünde $\mathrm{ACE}$ C18 kolon kullanılarak DAD detektörüyle yapılmıştır (Moghbel ve ark., 2015; Kınay, 2018). Fenolik (klorojenik ve rutin) içerikleri yine HPLC cihazinda $7.7 \times 300 \mathrm{~mm}, 8 \mu \mathrm{m}$ C-18 kolon kullanılarak DAD detektörüyle yapılmıştır (Cirak ve ark., 2016; Kınay, 2018). Ağır metal miktarları ise kuru tütün yaprakları agat değirmeninde ögütülmüsş, öğütülen örneklerden $0.2 \mathrm{~g}$ tartılarak mikrodalga cihazında (Mars Xpress) yaş yakma metoduna göre $\mathrm{H} 2 \mathrm{O} 2-\mathrm{HNO} 3$ asit karışımında yakılmıştır. Daha sonra bu örneklerde ICPOES (Thermo Icap-7400) cihazında kadmiyum, arsenik ve kükürt elementlerinin okuması yapılmıştır (Kaçar ve İnal, 2008). Elde edilen bulgularda güven sinırları belirlenmiştir (Yurtsever, 1984).

\section{Bulgular ve Tartışma}

Yapılan araştırmada Adıyaman, Batman, Bitlis, Diyarbakır, Hatay, Malatya, Mardin ve Muş illerinden toplanan kuru tütün yaprakları içeriğindeki kükürt miktarları belirlenerek \%95 güven aralığına göre 
istatistiki analize tabi tutulmuştur (Çizelge 1). Çalışma ortalaması $4340.46 \mathrm{ppm}$ alt ve üst sınır değerleri sırasıyla 3908.26-4772.67 ppm olarak bulunmuştur. Çalışmada alt ve üst sınır değerleri arasında kalan aralık Türkiye’de sarmalık kıyılmış tütün üretimi yapılmakta olan bölgeyi temsil edebilmektedir. Araştırmada belirlenen kükürt seviyeleri TSE standartları ve daha önceki çalışmalara göre 3000 ppm seviyesine kıyasla çok yüksek ve istenilen değer sınırının üzerinde olduğu sonucu çıkmıştır (Üren, 2011). Sadece 3 noktadaki tütünlerin kükürt içeriklerinin sınır değerler içerisinde olduğu belirlenmiştir. $\mathrm{Bu}$ nedenle çalışmanın yürütüldüğü alanlardaki tütün üretiminde yoğun kükürt kullanımının olduğu tespit edilmiştir. $\mathrm{Bu}$ değerlerin sağlık açısından üst sınırın üzerinde olduğunu göstermektedir.

Kadmiyum tütün bitkisi içeriğinde bulunan önemli ağır metallerden biridir. Çalışmada kadmiyum alt sınır değeri $0.345 \mathrm{ppm}$, üst sınır değeri $0.548 \mathrm{ppm}$ ve ortalama ise $0.447 \mathrm{ppm}$ olarak bulunmuştur. Çalışmada alt ve üst sınır değerleri arasında kalan 8 köy sınır değerler içerisinde yer almaktadır. Çalışmada elde edilen $0.447 \mathrm{ppm}$ seviyesindeki kadmiyum dünyada referans değeri olarak kabul edilen $1.7 \mu \mathrm{g}(1.700 \mathrm{ppm})$ değerine kıyasla daha düşük düzeydedir. Ayrıca örneklerin toplandığı noktaların tamamının dünya referans değerinin altında olduğu görülmüştür.

Çizelge 1. Sarmalık kıyılmış tütün örneklerinin kükürt, kadmiyum ve arsenik miktarları

Table 1. Sulfur, cadmium and arsenic content of roll your own tobacco samples

\begin{tabular}{|c|c|c|c|c|}
\hline No & Örnek noktaları & Kükürt (ppm) & Kadmiyum (ppm) & Arsenik (ppb) \\
\hline 1 & Malatya-Kurucaova & 3783.21 & 0.3134 & 209.40 \\
\hline 2 & Malatya-Gedikağzı & 5244.64 & 0.7303 & 171.37 \\
\hline 3 & Malatya-Fındık & 3802.57 & 10.344 & 56.40 \\
\hline 4 & Malatya-Merkez & 3917.12 & 0.5990 & 48.67 \\
\hline 5 & Mardin-Kocalar & 2987.87 & 0.4695 & 261.32 \\
\hline 6 & Mardin-Yüceler & 3155.98 & 0.3363 & 153.13 \\
\hline 7 & Mardin-Merkez & 3348.88 & 0.3057 & 199.48 \\
\hline 8 & Diyarbakır-Kızlar & 5070.70 & 0.3067 & 212.60 \\
\hline 9 & Diyarbakır-Çitlibahçe & 3406.95 & 0.2161 & 314.01 \\
\hline 10 & Diyarbakır-Çobantepe & 5547.83 & 0.4568 & 254.40 \\
\hline 11 & Diyarbakır-Sarıbuğday & 3518.87 & 0.4785 & 256.33 \\
\hline 12 & Adiyaman-Recep & 4958.28 & 0.6331 & 167.62 \\
\hline 13 & Adiyaman-Pinar & 3727.31 & 0.3265 & 260.27 \\
\hline 14 & Adiyaman-Yesiltepe & 4282.07 & 0.6693 & 274.86 \\
\hline 15 & Adıyaman-Merkez & 3260.06 & 0.3379 & 421.15 \\
\hline 16 & Muş-Köşk & 2985.92 & 0.5405 & 830.42 \\
\hline 17 & Muş-Ağartı & 2258.16 & 0.7010 & 375.83 \\
\hline 18 & Muş-Dumlusu & 4953.36 & 0.5618 & 329.69 \\
\hline 19 & Muş-Dedeyurt & 3396.25 & 13.621 & 285.69 \\
\hline 20 & Batman-Balbaşı & 3963.99 & 0.1201 & 117.48 \\
\hline 21 & Batman-Yeniköy & 4548.00 & 0.1200 & 75.36 \\
\hline 22 & Batman-Derince & 3840.80 & 0.1200 & 43.72 \\
\hline 23 & Batman-Ergünü & 4735.36 & 0.2000 & 153.68 \\
\hline 24 & Bitlis-Gölbaşı & 5128.92 & 0.3600 & 433.52 \\
\hline 25 & Bitlis-Kuşdili & 4809.52 & 0.3600 & 135.16 \\
\hline 26 & Bitlis-Arıdağ & 4947.68 & 0.5600 & 379.16 \\
\hline 27 & Bitlis-Söğüt & 6913.20 & 0.3200 & 240.80 \\
\hline 28 & Hatay-Yalaza & 5169.92 & 0.4400 & 10,44 \\
\hline 29 & Hatay-Görentaş & 7605.68 & 0.1600 & 376.80 \\
\hline 30 & Hatay-Çabala & 4944.16 & 0.2800 & 431.44 \\
\hline Ortalama & & 4340.46 & 0.4473 & 249.04 \\
\hline St. Hata & & 211.32 & 0.0490 & 29.84 \\
\hline Alt Değer & & 3908.26 & 0.3458 & 188.00 \\
\hline Üst Değer & & 4772.67 & 0.5488 & 310.08 \\
\hline
\end{tabular}


Başka bir ağır metal olan arsenik miktarları ortalaması $249.04 \mathrm{ppm}$ olarak bulunmuştur. Analiz sonuçlarına göre alt sınır değerinin 188.00 ppm ve üst sınır değerinin $310.07 \mathrm{ppm}$ olduğu belirlenmiştir. İstatistiki analizler sonucunda belirlenen alt ve üst sinır değerleri arasında kalan değer aralı̆̆ı, bölgeyi temsil eden değerler olup dünyada referans değeri olarak kabul edilen $2.4 \mu \mathrm{g}(2400 \mathrm{ppb})$ değerine kıyasla çok düşüktür. Buna göre belirlenen noktalar içinde 10 köy alt ve üst sınır değerlerinin arasında olduğu tespit edilmiştir.

Tütün için 2008 Tarih ve 27065 sayll resmi gazetede sigaralardaki nikotin oranı $1 \mathrm{mg}$ 'ın altında olması gerektiği yayınlaşmıştır. Araştırmada belirlenen noktalardan toplanan tütün yapraklarının içeriğindeki nikotin oranları ortalaması \%1.41 olan çalışmada alt ve üst sınır değerleri sırasıyla 0.97-1.86 olarak bulunmuştur. Belirlenen \%1.41 düzeyi sınır değer olan $1 \mathrm{mg}$ seviyesinin üzerindedir. Üst sınır değerinin üzerinde 9 köy bulunurken, alt sinır değerinin altında 16 köy bulunmaktadır. Ayrıca alt sınır değeri altında kalan 16 köy aynı zamanda $1 \mathrm{mg}$ seviyesinin de altında kalmaktadır.

Çizelge 2. Sarmalık kıyılmış tütün örneklerinin nikotin oranı, klorojenik asit ve rutin miktarları

Table 2. Nicotine ratio, chlorogenic acid and rutin content of roll your own tobacco samples

\begin{tabular}{|c|c|c|c|c|}
\hline No & Örnek noktaları & Nikotin (\%) & $\begin{array}{l}\text { Klorojenik asit } \\
\text { (ppm) }\end{array}$ & Rutin (ppm) \\
\hline 1 & Malatya-Kurucaova & 5.3 & 97.1 & 147.58 \\
\hline 2 & Malatya-Gedikağzı & 5.24 & 271.35 & 329.26 \\
\hline 3 & Malatya-Findık & 1.66 & 374.06 & 474.7 \\
\hline 4 & Malatya-Merkez & 1.77 & 251.1 & 442.98 \\
\hline 5 & Mardin-Kocalar & 3.17 & 315.7 & 597.83 \\
\hline 6 & Mardin-Yüceler & 0.82 & 297.16 & 532.08 \\
\hline 7 & Mardin-Merkez & 0.85 & 318.62 & 484.32 \\
\hline 8 & Diyarbakır-Kızlar & 0.87 & 372.58 & 458.46 \\
\hline 9 & Diyarbakır-Çitlibahçe & 0.83 & 350.38 & 564.71 \\
\hline 10 & Diyarbakır-Çobantepe & 1.02 & 536.59 & 506.93 \\
\hline 11 & Diyarbakır-Sarıbuğday & 0.73 & 473.35 & 575.87 \\
\hline 12 & Adıyaman-Recep & 1.54 & 827.62 & 596.91 \\
\hline 13 & Adıyaman-Pınar & 1.2 & 164.8 & 444.51 \\
\hline 14 & Adıyaman-Yeşiltepe & 1.96 & 242.63 & 332.08 \\
\hline 15 & Adıyaman-Merkez & 1.38 & 190.92 & 196.03 \\
\hline 16 & Muş-Köşk & 1.1 & 690.34 & 806.61 \\
\hline 17 & Muş-Ağartı & 0.8 & 437.56 & 545.67 \\
\hline 18 & Muş-Dumlusu & 0.96 & 350.39 & 401.22 \\
\hline 19 & Muş-Dedeyurt & 1.42 & 665.07 & 925.96 \\
\hline 20 & Batman-Balbaşı & 0.64 & 233.11 & 288.77 \\
\hline 21 & Batman-Yeniköy & 0.6 & 261.8 & 261.01 \\
\hline 22 & Batman-Derince & 1.15 & 305.82 & 412.03 \\
\hline 23 & Batman-Ergünü & 0.91 & 349.88 & 281.35 \\
\hline 24 & Bitlis-Gölbaşı & 0.8 & 450.82 & 506.04 \\
\hline 25 & Bitlis-Kuşdili & 0.88 & 627.18 & 634.23 \\
\hline 26 & Bitlis-Arıdağ 1 & 0.71 & 319.56 & 434.74 \\
\hline 27 & Bitlis-Söğüt & 0.95 & 659.84 & 835.19 \\
\hline 28 & Hatay-Yalaza & 0.65 & 76.84 & 243.91 \\
\hline 29 & Hatay-Görentaş & 0.46 & 52.89 & 89.86 \\
\hline 30 & Hatay-Çabala & 2.13 & 18.61 & 151.24 \\
\hline Ortalama & & 1.41 & 352.79 & 450.07 \\
\hline St. Hata & & 0.21 & 36.16 & 36.71 \\
\hline Alt Değer & & 0.97 & 278.83 & 374.98 \\
\hline Üst Değer & & 1.86 & 426.75 & 525.16 \\
\hline
\end{tabular}


Adıyaman, Batman, Bitlis, Diyarbakır, Hatay, Malatya, Mardin ve Muş illerinde yürütülen araştırmada belirlenen klorojenik asit ve rutin \% 95 güven aralığına göre istatistiki analize tabi tutulmuştur. Klorojenik asit ortalaması $352.79 \mathrm{ppm}$, alt ve üst sınır değerleri sırasıly 278.83-426.75 ppm olarak bulunmuştur (Çizelge 2). Yapılan araştırmada alt ve üst sınır değerleri arasında kalan aralık çalışma yaptığımız bölgeyi temsil eder niteliktedir. Buna göre 10 köy alt sınır değerinden daha az ve 9 köy üst değerden daha fazla klorojenik asit içeriğine sahip olurken 11 köy sınır değerler arasında yer almıştır. Rutin için çalışma ortalaması $450.07 \mathrm{ppm}$, alt ve üst sinır değerleri sirasıyla 374.98-525.16 ppm olarak belirlenmiştir. Fenolik maddeler tütün kalitesine olumlu yönde etki etmektedir (Kurt, 2019).

Çalışma esnasında çiftçilerle yapılan yüz yüze görüşmeler sonucunda, tütün yetiştiriciliğinde çiftçilerin $\% 100$ 'ünün hayvan gübresi, bunun yanında ek olarak $\% 50$ 'sinin diamonyum fosfat ve üre gibi kimyasal gübrelerden dekara 8-12'şer $\mathrm{kg}$ kullandığ belirlenmiştir. Çiftçilerin yetiştiricilikte kullandıkları gübre miktarı oryantal tütün yetiştiriciliği için gerekli olandan (Kınay, 2010) fazladır. Tütün yetiştiriciliği yapan çiftçilerin \% 90'1 vejetasyon süresi boyunca 7-8 kez sulama yaparken, \%10'u tarlaya dikim sırasinda sadece can suyu vermektedir. Çiftçilerin tamamı çiçeklenme döneminde tepe kırma işlemi yapmaktadırlar. Tütünü olgunlaştırmak ve sarartmak için \%15’lik kesim dekara 8-10 kg kükürt attığını ifade ederken, yaprağı sarartmak için kullandıkları kükürt

\section{Teșekkür}

$\mathrm{Bu}$ çalışma Tokat Gaziosmanpaşa Üniversitesi Bilimsel Araştırma Projeleri Komisyonu tarafından 2017/52 no ile desteklenmiştir

\section{Kaynaklar}

Aşut, Ö., 1993. Hekim ve sigara. Türk Tabipler Birliği Yayınları. Maya Matbaacılık ve Yayıncılık Ltd. Şti. Ankara, 1. Bask1, s: 43-52.

Ayan, F., 2008. Sigaranın zararları ve sigarayı bırakmanın yararları. İ.Ü. Cerrahpaşa Tıp Fakültesi Sürekli Tıp Eğitimi Etkinlikleri Kardiyoloji Gündemi Sempozyumu, 43-52, 7-9 Mart, Antalya.

Ball, S., Lloyd, L., 2011. Agilent hi-plex columns for carbonhydrates, alcohols, and acids. Application Note. Pub., 4: 5990-8264

Cirak, C., Radusiene, J., Jakstas, V., Ivanauskas, L., Seyis, F., Yayla, F., 2016. Secondary metabolites of seven Hypericum species growing in Turkey, Pharmaceutical Biology, 54(10): 2244-2253.

Çiçek, A., Erkan, O. 1996. Tarım ekonomisinde araştırma ve örnekleme yöntemleri, TOGÜ, Ziraat Fakültesi Yayınları No:12, Ders Notları Serisi No:6, Tokat. miktarını belirtmekten kaçınmış ve bazı üreticiler ise hiç kullanmadıklarını ifade etmişlerdir.

\section{Sonuç}

Türkiye'de sarmalık kıyılmış tütün üretimi yapılmakta olan Adıyaman, Batman, Bitlis, Diyarbakır, Hatay, Malatya, Mardin ve Muş illerinde yürütülen bu araştırmada tütün örneklerinde kimyasal kalite değerleri belirlenerek dünyada kabul gören referans değerlerin içerisindeki yeri tespit edilmiştir. Araştırmada incelenen kimyasal özelliklerden nikotin ve kükürt içerikleri referans değerlerin üzerinde, arsenik ve kadmiyum değerleri ise altındadır. Önemli sağlık sorunlarına neden olabilen bu bileşiklerin miktarları çiftçilerin yetiştiricilik esnasında yaptıkları uygulamalar ile doğrudan ilişkilidir. Tütünde kimyasal kaliteyi olumlu yönde etkileyen fenolik bileşiklerden klorojenik asit ve rutin içerikleri oryantal tütünlere göre düşük olmasına rağmen, yetiştiricilik yöntemi benzerlik gösteren burley tütünlerinden daha yüksektir. Türkiye'de üretilmekte ve satılmakta olan sarmalık kıyılmış tütünlerin üretim ve satış sürecindeki denetim yetersizliği, insan sağlığını tehdit etmekte ve ülke ekonomisine zarar vermektedir. Sarmalık kıyılmış tütünlerin bazı kimyasal bileşenlerinin konu edildiği çalışma ile Türkiye'de bu konuda ilk bilgiler raporlanmıştır. Son y1llarda artan tüketimi de göz önünde bulundurulduğunda Türkiye'de sarmalık kıyılmış tütünlerin referans değerleri ivedilikle belirlenmeli, bu tütünler tüm yönleriyle çalışmalara konu edilmelidir.
Er, M., 2016. Sigara dumanındaki zararlı maddeler. http://yunus.hacettepe.edu.tr/ muer/ (Erişim tarihi: 10 Nisan 2018).

Fitzpatrick, T.M., Blair, E.A., 2000. Upper airway complications of smoking. Clin. Chest. Med., 21: 147-157.

Gazioğlu, K., 1997. Akciğer hastalıkları. Nobel Kitabevi. 206 s, İstanbul.

Jung, M.C., Thornton, I., Jhon, H.T., 1998. Arsenic, cadmium, copper, lead, and zinc concentrations in cigarettes produced in Korea and the United Kingdom. Environmental Technology, 19(2): 237241

Kacar, B., İnal, A., 2008. Bitki Analizleri, Nobel Yayın Dağıtım, 2. Baskı, 912 s, Ankara.

Kayaalp, O.S., 1997. Rasyonel tedavi yönünden tıbbi farmakoloji. Hacettepe ÜTF Yayınları, 7. Bask1, 920 s, Ankara. 
Kınay, A., 2010. Effects of different nitrogen rates on yield and quality of tobacco (Nicotiana tabacum L.). M. Sc. Thesis. Gaziosmanpasa University, Graduate School for Applied Sciences, p.52, Tokat.

Kınay, A., 2018. Effects of cadmium on nicotine, reducing sugars and phenolic contents of basma tobacco variety. Fresenius Environmental Bulletin. 27(12A): 9195-9202.

Kurt, D., 2019. Seçilmiş Üstün Özellikli Basma Tip Tütün (Nicotiana tabacum L.) Hatlarının Genotip x Çevre İnteraksiyonları. PhD Thesis. Gaziosmanpaşa Üniversitesi, Fen Bilimleri Enstitüsü, 213s, Tokat.

Moghbel, N., Ryu, B., Steadman, K.J., 2015. A reversed-phase HPLC-UV method developed and validated for simultaneous quantification of six alkaloids from Nicotiana spp. Journal of Chromatography B, 997: 142-145.

Mussalo-Rauhamaa, H., Salmella, S.S., Leppanen, A., 1986. Cigarettes as a source of some trace and heavy metals and pesticides in man. Arch. Environ. Health, 41(1): 49-55

Oral, H., 2010. Kimyasal katk1 maddeleri ve tarım ilaçları kullanılmadan şark tipi tütünler ile doğal sigara üretimi. U. Ü. Ziraat Fakültesi Dergisi, 24(2): 149-155

Söylemez, E., 2011. Sigara kullananlarda kan kadmiyum düzeyi ve lenfosit dna hasarının belirlenmesi. Yüksek Lisans tezi. Ankara Üniv. Sağlık Bil. Enst., 79s, Ankara.

Üren, E., 2011. Kükürt dioksitin genotoksik etkilerinin araştırılması. Yüksek lisans tezi. İnönü Üniversitesi Sağlık Bilimleri Enstitüsü, 86s, Malatya.

Yurtsever, N. 1984. Deneysel ve istatistik metotlar. Köy Hizmetleri Genel Müdürlüğü Yayınları Genel Yayın No:121 Teknik Yayın No:56, 623 s, Ankara.

Zhu, B,. Sun, Y., Sievers, R.E., Shumon, S.L., Glontz, Z.A., Chotlarjee, K., Pormley, L.W.W., 1996. Wolfe, larginine tecreases infact. Size in rots exposed to enviromental tobacco smoke. Am. Hearts Jour., 132: 91-100 